\title{
What is the Future of Pediatric Neurology in Canada? Resident and Faculty Perceptions of Training and Workforce Issues
}

\author{
Asif Doja, Chantalle Clarkin, Sharon Whiting, Mahendranath Moharir
}

\begin{abstract}
Background: Pediatric neurology trainee numbers have grown considerably in Canada; recent research, however, has shown that the number of pediatric neurology graduates is outpacing the need for future pediatric neurologists. The purpose of this study was to seek the opinion of pediatric neurology program directors and trainees regarding possible solutions for this issue. Methods: Two focus groups were convened during the Canadian Neurological Sciences Federation annual congress in June 2012; one consisted of current and former program directors, and the other of current pediatric neurology trainees. Groups were asked for their perceptions regarding child neurology manpower issues in Canada as well as possible solutions. Focus groups were audio-recorded and transcribed for analysis. Theme-based qualitative analysis was used to analyze the transcripts. Results: Major themes emerging from both focus groups included the emphasis on community pediatric neurology as a viable option for trainees, including the need for community mentors; recognizing the needs of underserviced areas; and establishing academic positions for community preceptors. The need for career mentoring and support structures during residency training was another major theme which arose. Program directors and trainees also gave examples of ways to reduce the current oversupply of trainees in Canada, including limiting the number of trainees entering programs, as well as creating a long-term vision of child neurology in Canada. Conclusions: A nationwide dialogue to discuss the supply and demand of manpower in academic and community pediatric neurology is essential. Career guidance options for pediatric neurology trainees across the country merit further strengthening.
\end{abstract}

RÉSUMÉ: Quel est l'avenir de la neurologie pédiatrique au Canada ? Perceptions des médecins résidents et du corps professoral en ce qui regarde les enjeux liés à la formation et aux effectifs. Contexte: Le nombre de stagiaires en neurologie pédiatrique a considérablement augmenté au Canada. Toutefois, une étude récente a montré que le nombre de finissants ayant été formés dans ce domaine dépasse les besoins en futurs neurologues pédiatriques. L'objectif de cette étude a donc consisté à solliciter l'avis des directeurs de programmes en neurologie pédiatrique et des stagiaires, ainsi que leurs pistes de solution, face à cette situation. Méthodes: Deux groupes de discussion (focus groups) ont été constitués à l'occasion du congrès annuel de la Fédération canadienne des sciences neurologiques tenu en juin 2012. Un de ces groupes regroupait d'anciens et d'actuels directeurs de programmes en neurologie pédiatrique tandis que l'autre regroupait de jeunes médecins alors stagiaires en neurologie pédiatrique. On a demandé aux participants de faire part de leurs impressions concernant les enjeux qui touchent la relève au Canada et à exprimer des pistes de solution. Ces groupes de discussion ont fait l'objet d'un enregistrement audio et ont été transcrits aux fins d'analyse. Les transcriptions ont ensuite été analysées thématiquement de façon qualitative. Résultats: Parmi les principaux thèmes ayant émergé, on peut citer l'accent mis sur la neurologie pédiatrique communautaire comme option valable pour les stagiaires, ce qui sous-tend le besoin de mentors communautaires. Il a aussi été question de reconnaître les besoins des régions insuffisamment desservies et de créer des postes universitaires de précepteurs communautaires. Les besoins en mentorat professionnel et en structures de soutien durant le programme de formation en résidence a été un autre thème important évoqué. Les directeurs de programmes et les stagiaires ont aussi fourni des exemples de mesures qui permettraient de réduire l'excédent actuel de stagiaires au Canada, notamment en limitant le nombre de personnes candidates et en forgeant une vision à long terme de la neurologie pédiatrique au Canada. Conclusions: Un dialogue à l'échelle nationale pour discuter de l'offre et de la demande en ce qui concerne les effectifs en neurologie pédiatrique demeure essentiel, et ce, tant à l'université que sur le plan communautaire. L'orientation professionnelle des stagiaires en neurologie pédiatrique au pays mérite aussi d'être davantage consolidée.

Keywords: Postgraduate Training, Manpower, Child Neurology

doi:10.1017/cjn.2016.6

Can J Neurol Sci. 2016; 43: 549-553

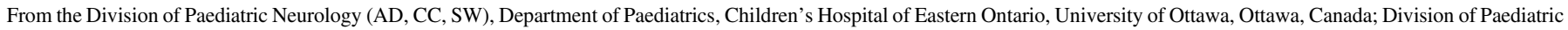
Neurology (MM), Department of Paediatrics, The Hospital for Sick Children, University of Toronto, Toronto, Canada.

Received February 2, 2015. Final Revisions Submitted November 26, 2015. Date of Acceptance December 13, 2015.

Correspondence to: Asif Doja, Assistant Professor, Division of Neurology, Children's Hospital of Eastern Ontario, 401 Smyth Rd, Ottawa, Ontario, K1H 8L1.

Email: adoja@cheo.on.ca 


\section{Table 1: Semistructured questions used in focus groups}

\begin{tabular}{|c|c|}
\hline Program director group & Pediatric neurology trainee group \\
\hline $\begin{array}{l}\text { 1) What are your opinions regarding the number of pediatric neurology graduates } \\
\text { with respect to the job prospects in pediatric neurology training programs in the } \\
\text { next } 5 \text { to } 10 \text { years? }\end{array}$ & $\begin{array}{l}\text { 1) What are your opinions regarding the number of pediatric neurology graduates with respect } \\
\text { to the job prospects in pediatric neurology training programs in the next } 5 \text { to } 10 \text { years? }\end{array}$ \\
\hline $\begin{array}{l}\text { 2) What possible solutions can you envision regarding this gap between salaried } \\
\text { academic job positions for pediatric neurologists and the number of graduates? }\end{array}$ & $\begin{array}{l}\text { 2) What can individual programs do to address this gap between salaried job positions for } \\
\text { pediatric neurologists and the number of graduates? }\end{array}$ \\
\hline 3) What can individual programs do to address these issues? & 3) How adequate is career counseling in your pediatric neurology training program? \\
\hline $\begin{array}{l}\text { 4) What role does community pediatric neurology play as a possible solution to these } \\
\text { issues? }\end{array}$ & $\begin{array}{l}\text { 4) What can individual programs do to encourage more exposure to community pediatric } \\
\text { neurology? }\end{array}$ \\
\hline $\begin{array}{l}\text { 5) How can individual programs encourage exposure to community pediatric } \\
\text { neurology? }\end{array}$ & \\
\hline
\end{tabular}

Pediatric neurology training programs have grown substantially in Canada over the past decade. In 2001, there were three or four pediatric neurology training programs in Canada, each graduating one pediatric neurologist per year. ${ }^{1}$ However there are currently ten pediatric neurology programs in Canada, ${ }^{2}$ and at the last formal estimate in 2012, there were 38 residents enrolled in postgraduate training in pediatric neurology in Canada. $^{3}$ A recent survey indicated that the current number of pediatric neurology graduates is outpacing the projected need for future pediatric neurologists. ${ }^{3}$ This study, however, had significant limitations. It focused strictly on estimating the number of future pediatric subspecialty positions in academic centers by asking chairs of pediatrics departments across Canada to estimate the number of academic positions they envisioned being able to provide for various subspecialties over the next 5 years. They then compared this with the number of trainees enrolled in all pediatric subspecialty training programs. They did not factor in variables such as differences in fellowship structure, job profile (clinical-research-education split), nor were questions directed at availability of community positions. The survey also did not examine the clinical demand for subspecialties. Thus, although it is unclear whether we are training too many or too few pediatric neurologists in Canada, a shortage of academic positions appears imminent.

The purpose of this study was to seek the opinion of pediatric neurology program directors regarding possible solutions to address this gap between the need and available human resources, including their thoughts on encouraging more exposure to community neurology. Similarly, we sought the opinion of current pediatric neurology trainees regarding their perceptions of how training programs could help to address this issue.

\section{METHODS}

The study team comprised three experienced pediatric neurologists (one current program director, one former program director, and one division chief). During the conceptualization phase of the study, the research team assembled to discuss its views, acknowledge its individual assumptions, and examine its presuppositions on training and workforce issues. This critical and reflexive dialogue aimed to reduce orientation bias, ${ }^{4}$ and continued throughout data collection and interpretation.

Additionally, an experienced qualitative researcher and nurse (CC) moderated the focus group sessions and led the preliminary analysis. Although the investigator's background in health care informed some of the emergent discussion and analysis, this author was outside the field of pediatric neurology.

Two focus group sessions were held during the Canadian Neurological Sciences Federation (CNSF) annual congress, between June 6 and 8, 2012, in Ottawa, Ontario. One focus group was conducted with pediatric neurology program directors and the other was conducted with pediatric neurology trainees. Because of the exploratory nature of the study, semistructured and open-ended questions were used to elicit discussion and interaction among focus group participants. The questions used to guide the focus groups are presented in Table 1. These questions were developed based on a combination of expert opinion and the past literature. ${ }^{1-3}$ For the purposes of this study, "community neurologists" are defined as those who spend $>50 \%$ of their clinical time practicing outside of an academic center. Additionally, this term was used to only refer to individuals who spent the majority of their time practicing pediatric neurology, as opposed to general pediatrics, adult neurology, or developmental pediatrics. Similarly, "academic positions" can be considered full-time or full-time equivalent positions at an academic center.

Sessions were facilitated by a trained qualitative researcher with experience in focus group moderation. The focus groups were audio-recorded and transcribed for analysis. Anonymized transcripts were entered into NVivo10 (QSR International) to facilitate data reduction and organization. Theme-based, inductive qualitative analysis was used to analyze the data. During analysis, the two research team members read through the transcripts to gain an overall sense of the data, note patterns and recurrences, and reflect on preliminary interpretations. The team then met to discuss its perceptions and review the initial coding scheme. Once agreement was reached about the coding scheme, transcripts were reanalyzed to identify instances of the themes and abstract illustrative quotes. To enhance the trustworthiness of the findings, the researchers also maintained an audit trail of coding decisions and data analysis procedures and evolving coding schemes. ${ }^{5}$

\section{Subject Selection}

All Canadian neurology program directors listed on the College of Physicians and Surgeons of Canada (RCPSC) website were sent an information sheet and consent form inviting them to participate in the focus group. If they were unable to attend the $\mathrm{CNSF}$ conference, they were asked to identify a delegate to attend 


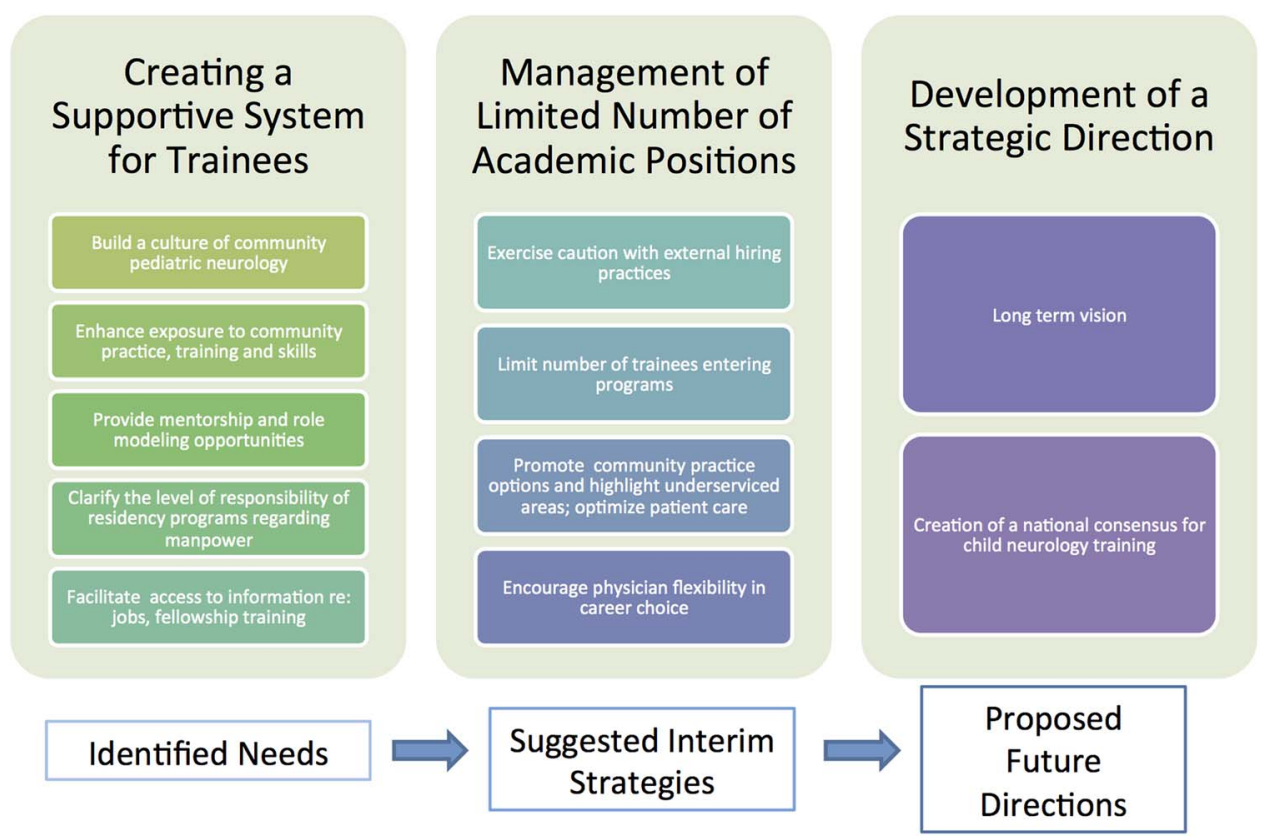

Figure 1: Summary of themes arising from focus group.

the focus group in their place. The delegate was required to be a practicing pediatric neurologist at his or her respective institution with involvement in the medical education of trainees. We also asked the program directors to distribute an email to their current pediatric neurology trainees containing a study information letter and invitation to participate, as well as a consent form. This study was approved by the Children's Hospital of Eastern Ontario Research Institute's Research Ethics Board.

\section{RESUltS}

There were six participants in the program director focus group (five current and one previous program director) and they represented academic centers with catchment areas of between 6.6 and 1.8 million persons. There were seven participants in the trainee focus group. Several themes were expressed by both focus groups; these are summarized in Figure 1. There were three major themes identified, including creating a supportive system for trainees, management of a limited number of positions, and development of strategic direction, with each of these themes being composed of various subthemes.

\section{Creating a Supportive System}

This theme centered around the need for a training program to provide career support an mentoring throughout training, including providing adequate career counseling for trainees and increasing exposure to community pediatric neurology. Five subthemes were noted including: building a culture of community pediatric neurology; enhancing exposure to community practice, training, and skills; providing mentorship and role modeling opportunities; clarifying the responsibility of residency programs regarding manpower issues; and facilitating access to information regarding jobs and fellowship training.
The theme of building a culture of community pediatric neurology encompassed the idea of including community pediatric neurologists as teachers in training programs and valuing their contributions:

The issue that comes up...through adjunct faculty people,... is...'I'm perfectly happy doing my work. I'm doing this as a favor, and if it's ever inconvenient for me, I'm not going to do it." So, there's a real problem with retention of community faculty. And unfortunately the universities don't have a good sustainability plan for these faculty whom they're becoming much more dependent on now with the expansion of the medical schools.

Staff Focus Group, June 2012

Enhancing exposure to community practice, training, and skills was suggested as a viable way to help trainees gain exposure to community pediatric neurology. Additionally, providing mentorship and role modeling opportunities was noted as an important step in encouraging career choice, particularly for community pediatric neurology. Participants were aware that, without adequate exposure to good community role models, trainees may have skewed perceptions of community practice:

And I think part of it is having good role models. People that are excellent community neurologists who are just as smart as everyone else that chose that path, rather than you know... the perception...is that it's somehow a second-class kind of thing.

Staff Focus Group, June 2012

Overall, the trainee group in particular felt that career counseling as a whole could be improved in training programs: 
The Royal College falls short of giving any sort of obligation for career counseling, as a mandate of the actual residency training program. And I think that gives the individual programs a lot of leeway to kind of play fast and loose with what their obligations are to you in terms of career counseling, whether it's lots, a little, or nothing.

Trainee Focus Group, June 2012

Similarly, trainees felt that there was a need to facilitate access to information re: jobs and fellowship training. Many trainees felt that they only heard about these types of positions in a haphazard way and that a more formalized process or registry was needed.

\section{Management of a Limited Number of Positions}

This theme concerned interim strategies to best address the projected limited numbers of academic pediatric neurology positions. There were four subthemes identified: exercise caution with external hiring practices; limit the number of trainees entering programs; promote community practice options and highlight underserviced areas; optimize patient care; and encourage physician flexibility in career choice.

Trainees in particular expressed the theme of divisions of neurology needing to exercise caution with external hiring practices. "External" trainees meant that divisions may want to consider how hiring individuals from outside of Canada may affect the availability of positions for trainees who completed their residency in Canada. Both groups suggested that programs may want to limit the number of trainees entering programs, although neither group specified how many trainees would be ideal, nor who would ultimately decide on these limits.

Promote community practice options and highlight underserviced areas and optimize patient care encompassed the idea that we need to look at the best ways to address the discrepancy between the perceived lack of academic positions with continued patient need. This may mean encouraging more trainees to go into community practice. Even more specifically it may mean targeting certain areas that are particularly underserviced and encouraging trainees to set up practice there. All of this would be in an effort to optimize care and ensure that patients are being seen by pediatric neurologists in a timely fashion:

I think that's one of the real keys because it really strikes me. This paradox really strikes me... of the...six months to a year waiting list with many neurologists and the lack of...the perceived lack of work.

Staff Focus Group, June 2012

The final subtheme was encourage physician flexibility in career choice. This theme covers the concept that trainees may need to understand that with the limitations in academic positions, becoming subspecialized in a very specific area may not make them marketable. Programs need to ensure trainees are taking all aspects into account when making career choices.

\section{Development of a Strategic Direction}

This theme explored the need for a coordinated, national plan to examine neurology manpower in Canada. This comprised the subthemes of long-term vision and creating a national consensus for child neurology training.

The idea of a long-term vision is that we need to realistically be able to gauge patient need and pediatric neurology manpower for the short-, medium-, and long-term in Canada:

We hear all these rumblings, or at least I do, from my staff that that...that needs to change. That... there's just such a high volume of pediatric neurology clinically, that we're going to need more people in the community to deal with the more simple...pediatric neurology issues and then have the people who are in academic centers be doing a lot more research and all the academic type interests. So, they say that, but I don't think that there's actually been any decision on what sort of positions we should be trying to establish in pediatric neurology across the country and how best to serve that, both the clinical need and the academic need.

Trainee Focus Group, June 2012

Creating a national consensus for child neurology training builds on this idea, with the suggestion that based on the long-term vision, we should be able to establish agreement on issues such as trainee numbers. It also suggests that trainees should be able to have access to job postings, fellowships, and patient statistics to help them make informed career decisions.

It would be nice to have like a formalized national process, where things such as job prospects, or what not, those statistics are available. . .and before...I think before we start making decisions whether there are too many trainees or not, we have to know like the statistics.

Trainee Focus Group, June 2012

\section{Discussion}

Our study uncovered numerous themes regarding the perceptions of pediatric neurology program directors and trainees on workforce issues in Canada. Chief among them is the issue of career counseling for trainees. Although career counseling is mandated as part of the RCPSC standards, ${ }^{6}$ it is apparent that trainees desire more career counseling and guidance from programs. This may involve early discussions with respect to career paths, mentorship with faculty internal and external to their home programs, and exposure to different styles of pediatric neurology practice.

Increased exposure to community neurology was emphasized by both program directors and trainees. This, however, is predicated on the willingness of community preceptors to be involved with training programs. There are also financial considerations because preceptors traditionally require remuneration for their time. These financial concerns must be taken into account by residency training committees. Other incentives for community preceptors may include having positions on residency training committees or having an academic appointment at the institution in question (i.e. adjunct professorship).

Focus group participants suggested a number of interim strategies to address the issue of a limited number of academic 
positions; however, some of these strategies may be difficult to operationalize. Limiting the number of individuals hired from outside of Canada may not always be feasible. For example, divisions are sometimes recruiting very specific individuals, such as mid-career pediatric neurologists, basic science researchers, or those with a very specific subspecialty. It could very well be that new graduates from pediatric neurology programs in Canada may not be suitable candidates for these positions. Limiting the number of trainees entering programs may also not be feasible. If there is considerable patient demand for pediatric neurologists, with long waiting times for consultation, we may be doing patients a disservice by reducing numbers and thereby reducing the supply of pediatric neurologists.

There was widespread agreement across focus groups regarding the critical importance of developing a long-term vision and establishing consensus on pediatric neurology training. However, this raises questions regarding issues of representation, organization, and shared decision-making. For example, should the vision of child neurology emanate from the program directors, the RCPSC, the Canadian Association of Child Neurologists, or some other group? How can a consensus be enforced? How does one ensure all stakeholders have their views represented?

Our study was limited because of the small numbers in each focus group; however, we still were able to reach saturation of themes. One must also take into account that we may have been drawing from a sample with a particular viewpoint. For example, the residents in our focus group were motivated enough to not only attend the CNSF congress, but then to attend a separate focus group. These individuals thus may have had very strong opinions regarding the issues discussed. Similarly, it would have been ideal to include community pediatric neurologists in the focus groups to better understand their viewpoints on workforce issues.

\section{Future Directions}

Clearly, more information is needed to help programs and trainees address workforce issues in child neurology training in Canada. Preliminary steps in gathering this information include a recent survey of Canadian program directors and trainees in child neurology and the establishment of consensus recommendations. ${ }^{7}$ However, future study will need to focus on the feasibility of practicing community pediatric neurology in various parts of the Canada, in addition to how best to incorporate community practice into postgraduate child neurology training.

\section{Disclosures}

The authors do not have anything to disclose.

\section{REFERENCES}

1. Keene DL, Humphreys P. Inventory of pediatric neurology "manpower" in Canada. Can J Neurol Sci. 2005;32(3):306-10.

2. Doja A. Pediatric neurology training in Canada: current status and future directions. Can J Neurol Sci. 2012;39:369-77.

3. Piedboeuf B, Jones S, Orrbine E, Filler G. Are the career choices of paediatric residents meeting the needs of academic centres in Canada? Paediatr Child Health. 2012;17:17-20; A.

4. Kaptchuk TJ. Effect of interpretive bias on research evidence. BMJ. 2003:1453-5.

5. Rodgers BL, Cowles KV. The qualitative research audit trail: a complex collection of documentation. Res Nurs Health. 1993; 16(3):219-26.

6. Royal College of Physicians and Surgeons of Canada. Proposed Document. General standards applicable to all residency programs: B standards. 2011 [cited 2014 Nov 11]. Available from: http:// www.royalcollege.ca/portal/page/portal/rc/common/documents/ accreditation/accreditation_blue_book_b_standards_e.pdf.

7. Doja A, Orr SL, McMillan HJ, Kirton A, Brna P, Esser M, et al. Canadian Paediatric Neurology Workforce Survey and Consensus Statement. Can J Neurol Sci. Epub 2016 Jan 20. doi:10.1017/ cjn.2015.360. 